\title{
Assessment of patient satisfaction after levonorgestral containing intrauterine system insertion in women with abnormal uterine bleeding
}

\section{Anupama Dave, Kirti Sinha, Nidhi Gupta*}

Department of Obstetrics and Gynaecology, M. G. M. Medical College and M. Y. Hospital, Indore, Madhya Pradesh, India

Received: 28 October 2021

Revised: 29 November 2021

Accepted: 30 November 2021

\author{
*Correspondence: \\ Dr. Nidhi Gupta, \\ E-mail: nidhi.gupta2210@gmail.com
}

Copyright: ( ) the author(s), publisher and licensee Medip Academy. This is an open-access article distributed under the terms of the Creative Commons Attribution Non-Commercial License, which permits unrestricted non-commercial use, distribution, and reproduction in any medium, provided the original work is properly cited.

\begin{abstract}
Background: Abnormal uterine bleeding is a common gynecological complaint affecting 10-30\% of reproductiveaged women and it can result from different causes which adversely affects the woman's quality of life, necessitating its appropriate and adequate management. Among all the pharmacological and surgical management options of AUB. LNG-IUS is emerging as a safer and effective treatment option of AUB. However apprehension about discomfort associated with the use of intrauterine device leads to its untimely removal. Aim of current study was to conduct a prospective qualitative study to observe the level of patient satisfaction with the use of LNG-IUS in patients with abnormal uterine bleeding.

Methods: This study was conducted in the department of obstetrics and gynecology, MGM medical college and M.Y. Group of Hospitals, Indore from March 2017- March 2018. Follow up was done at 1, 3, 6 months.

Results: In our study, majority of the women $(90 \%)$ had improvement in their abnormal uterine bleeding along with significant increase in mean hemoglobin level from $7.30 \pm 1.29 \mathrm{gm} \%$ to $8.71 \pm 1.27 \mathrm{gm} \%$ at the end of six months. $86.66 \%$ of these patients were very satisfied with the use of LNG IUS,

Conclusions: LNG-IUS is an effective device for medical management of AUB and it should be used as the first line therapy for the same. It should always be considered before surgical interventions. It yields promising result in terms of patient satisfaction.
\end{abstract}

Keywords: LNG-IUS, Abnormal uterine bleeding, Gynecology

\section{INTRODUCTION}

Abnormal uterine bleeding (AUB) is a common gynecological complaint that is reported to occur in 10$30 \%$ of reproductive-aged women. ${ }^{1}$ Prevalence of AUB is reported to be around 17.9 amongst the gynaecology patients observed in the MYH OPD from March 2017 to march 2018. ${ }^{2}$ The abnormal bleeding patterns can adversely affect the woman's quality of life, it thus necessitates urgent appropriate and adequate management. ${ }^{1}$ Apart from bleeding related to pregnancy, abnormal uterine bleeding can result from different structural (e.g. polyp) as well as systemic (e.g., Von Willebrand's disease) causes or may be iatrogenic. ${ }^{3}$ LNG-IUS has been found to be more effective than usual medical treatment like mefenamic acid, tranexamic acid, combined estrogen-progestogen etc in reducing the effect of heavy menstrual bleeding on quality of life. It has also 
shown therapeutic effects comparable to endometrial ablation. So now days, by virtue of its efficacy, ease of use and cost effectiveness, LNG-IUS is considered as the first line medical therapy for the treatment of heavy menstrual bleeding whether the patient may or may not have any associated co morbidity. It is a onetime procedure and follow up is comparatively easy and hence patient compliance and satisfaction is greater. Amongst the different treatment options available for the treatment of AUB which includes both pharmacological and surgical methods, levonorgestrel-releasing intrauterine system (LNG-IUS) is a new and effective modality. However the general apprehension about intra uterine devices and the complication of unruly bleeding episodes has made it less acceptable. Hence we aim to evaluate weather proper counselling can lead to better acceptance and hence study the general satisfaction associated with its use.

\section{Aims and objectives}

Aim and objective of current study was to conduct a qualitative study to observe the level of patient satisfaction with the use of LNG-IUS in patients with abnormal uterine bleeding.

\section{METHODS}

The present study entitled was conducted in the department of obstetrics and gynecology, MGM medical college and MY group of hospitals, Indore from March 2017 to March 2018. It was a prospective study comprising 60 women who presented in MYH gynecology outpatient department with the complaint of AUB.

\section{Inclusion criteria}

All women in the reproductive age group who were married and had the complaint of abnormal uterine bleeding and with no cervical, vaginal pathology were included in the study.

\section{Exclusion criteria}

Women who had congenital or acquired uterine anomaly, women with leiomyoma (fibroids) distorting the uterine cavity, women with genital bleeding of unknown etiology, with known or suspected breast and endometrial carcinoma, women with acute pelvic inflammatory disease, with suspected pregnancy and women with acute liver disease and previous history of deep vein thrombosis were excluded from the study.

\section{Procedure}

After selecting the cases according to the inclusion criteria females giving consent for insertion of LNG IUS were subjected to detailed general and gynaecological examination. Complete hemogram was done. Pelvic ultrasound was also done to assess endometrial thickness and to look for any associated pathology. Endometrial biopsy was taken for histopathological reporting to rule out endometrial carcinoma. After all this, LNG-IUS was inserted on the outpatient basis except in few patients where cervix could not be visualised or in those patients who had other comorbid conditions requiring treatment, these patients were admitted to hospital for the insertion of LNG-IUS. Prior to insertion, patients were counselled regarding altered bleeding pattern, spotting and amenorrhoea known to occur with LNG IUS. They were called for follow up at first, third and sixth month of LNG IUS insertion and were subjected to detailed questionnaire about compliance, effect and satisfaction level regarding the symptomatic improvement as observed and experienced by the patients. The data was analysed using IBM SPSS25 software

\section{RESULTS}

The most common cause of AUB in study population was found to be idiopathic followed by adenomysis and fibroid. LNG IUS was useful in patients with comorbidities who were otherwise considered unfit for surgical management. At 1 month, most of the patients had spotting $(60 \%)$ and remaining $40 \%$ of the women had irregular heavy bleeding. At the end of 6 months, significant number (29) of the women developed amenorrhea while 14 had spotting, 8 had normal menstrual cycles, 3 had oligomenorrhea and only 2 had irregular heavy bleeding.

\section{Table 1: Distribution of cases according to demographic factors.}

\begin{tabular}{|c|c|c|}
\hline Parameters & \multicolumn{2}{|c|}{ Distribution amongst subjects (\%) } \\
\hline \multirow{3}{*}{ Age (years) } & $21-30$ & 10.0 \\
\hline & $31-40$ & 40.0 \\
\hline & $41-50$ & 50.0 \\
\hline \multirow{5}{*}{ Occupation } & House wife & 70.0 \\
\hline & Laborers & 15.0 \\
\hline & Service & 11.6 \\
\hline & Tailor & 1.7 \\
\hline & Teacher & 1.7 \\
\hline \multirow{2}{*}{ Literacy } & Literate & 13.3 \\
\hline & Illiterate & 43.3 \\
\hline \multirow{3}{*}{$\begin{array}{l}\text { Socio } \\
\text { economic } \\
\text { status }\end{array}$} & Lower & 36.7 \\
\hline & Middle & 35.0 \\
\hline & Upper middle & 28.3 \\
\hline \multirow{5}{*}{ Parity } & P0 & 1.7 \\
\hline & P1 & 10.0 \\
\hline & $\mathrm{P} 2$ & 40.0 \\
\hline & P3 & 25.0 \\
\hline & P4 and above & 23.3 \\
\hline
\end{tabular}

Six months after LNG-IUS insertion, 90\% women had improvement in their symptoms while there was no improvement in 2 women $(3.33 \%)$ even when LNG-IUS 
was in situ. LNG-IUS was expelled spontaneously in 2 patients while one patient got the device removed and one patient opted for hysterectomy. The number of very satisfied patient $(86.66 \%)$ are statistically significantly higher than number of satisfied $(6.67 \%)$ and not satisfied patients $(6.67 \%)$.

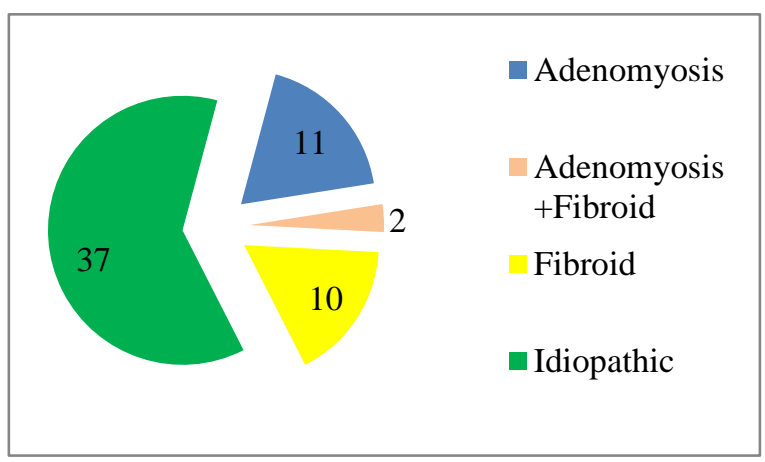

Figure 1: Distribution of cases according to etiology of AUB.

Table 2: Profile of comorbidities.

\begin{tabular}{|ll|}
\hline Comorbidities & $\%$ \\
\hline Hypertension & 8.3 \\
\hline Diabetes & 3.3 \\
\hline Severe anemia & 11.7 \\
\hline Hypothyroidism & 6.7 \\
\hline Others & 15.0 \\
\hline
\end{tabular}

\section{DISCUSSION}

AUB is common is a common gynecological complaint affecting about $10-15 \%$ of women at sometimes during the reproductive years of their lives. ${ }^{1,3}$ In our study, incidence of AUB in patients attending MYH gynecology OPD is nearly $17 \%$. Majority of them $(90.0 \%)$ belong to the age group of 31-50 years. This is same as a study done by Singh et al, where majority $(76.2 \%)$ of the women belonged to $30-50$ years of age. ${ }^{4}$ In our study, majority of the patients were housewife $(70 \%)$ and most of them were illiterate (26/60). Majority of the women belong to lower socioeconomic status $(36.7 \%)$. In our study majority of women were multiparous $(88.3 \%)$, this is same as in a study done by Dhamangaonkar et al where $81.4 \%$ patients were multiparous. ${ }^{5}$ As per the NICE guidelines on management of heavy menstrual bleeding, LNG-IUS is considered as the first line treatment for HMB in women with no identified pathology, fibroids less than $3 \mathrm{~cm}$ in diameter, or suspected or diagnosed adenomyosis. ${ }^{6}$ It can be used in submucosal fibroids not distorting the uterine cavity. So, in present study we used LNG-IUS in all these women. In our study, majority of patients $37(61.7 \%)$ had normal ultrasound findings followed by adenomyosis in $18.3 \%$ patients, fibroid in $16.7 \%$, adenomyosis and fibroid both in $3.3 \%$ patients whereas in the study by Dhamangaonkar et al $44.3 \%$ of the population had normal ultrasound findings followed by $37.1 \%$ with adenomyosis, $18.6 \%$ of the patients had fibroid, 3 patients $(4.3 \%)$ had associated bilateral adnexal endometriotric cyst of $2-2.5 \mathrm{~cm}$ and in the study by Singh et al $69 \%$ patients had dysfunctional uterine bleeding (normal ultrasound), $14.3 \%$ had fibroid uterus, 9.5\% patients had adenomyosis and rest patients had menorrhagia associated with endometriosis. ${ }^{4,5}$ LNG-IUS is an excellent treatment option for treating AUB in the morbid patients, where other medications are either contraindicated or fitness of surgery (hysterectomy) remains the main issue.

In the present study, severe anemia was present in $11.7 \%$ patients, hypertension in $8.3 \%$, hypothyroidism in $6.7 \%$ and diabetes in $3.3 \%$ patients. Others comorbidities like ascites, hepatomegaly, CVT, GTCS, h/o brain tumour, h/o stroke, psychiatric illness, ITP,MS, MR, piles polio, h/o surgery for oral cancer, portal HTN, spleenomegaly were present in $15 \%$ patients. In study by Dhamangaonkar et al $21.4 \%$ participants had hypertension, $8.6 \%$ had diabetes, $7.1 \%$ had thyroid, $8.6 \%$ had both hypertension and thyroid while $18.6 \%$ of the participants had some other comorbidities like bronchial asthma, human immunodeficiency virus (HIV), hepatitis $\mathrm{B}$, ischemic heart disease, valvular heart disease, epilepsy, and triple vessel disease. ${ }^{4,5}$ LNG-IUS decreases the amount of bleeding by $79-94 \% .^{2}$ It acts locally leading to high concentration of levonorgestrel in endometrium responsible for its therapeutic effect of decreasing blood loss during each cycle. ${ }^{7}$ But it takes about six cycles to see the benefits of treatment. ${ }^{6}$ In our study, the most common menstrual pattern at the time of presentation was menorrhagia in $38(63.3 \%)$ followed by irregular heavy bleeding in 14 (23.4\%) and polymenorrhoea in $8(13.3 \%)$ women. This was similar to the study by Dhamangaonkar et al $70 \%$ patient came to outpatient department with the complaint of menorrhagia, $21.4 \%$ came for polymenorrhea, $4.2 \%$ for menometrorrhagia (irregular heavy bleeding) and $4.2 \%$ patient came for dysmenorrhea. ${ }^{5}$ Regarding symptomatic relief, in our study there was a gradual but significant $(p<0.05)$ decrease in number of women with irregular heavy bleeding from $22(36.7 \%)$ at 1 month to 13 $(22.4 \%)$ at $3^{\text {rd }}$ month to only $2(3.4 \%)$ at the end of six months. Similar decrease was seen in women complaining of spotting, from $36(60 \%)$ at 1 month to 14 $(24.2 \%)$ at the end of six months $(\mathrm{p}<0.05)$ while there is a significant increase $(\mathrm{p}<0.05)$ in number of women with normal menstrual period, from none to $8(13.8 \%)$ at the end of 6 months and with oligomenorrhea/ amenorrhea, which increased from 0 at 1 month to 2 $(3.4 \%)$ at 3 month and $32(53.3 \%)$ at the end of six months. This is similar to study done by Numan et al where in the first 3 months, spotting was the most frequent menstrual finding. In our study, majority of the women $(90 \%)$ had improvement in their symptoms while there was no improvement in 2 women $(3.33 \%)$ even when LNG-IUS was in situ. In our study only 2 women had expulsion of LNG IUS during 1st menstrual cycle. 
Table 3: Bleeding pattern after LNG-IUS insertion.

\begin{tabular}{|c|c|c|c|c|}
\hline \multirow[b]{2}{*}{ Bleeding pattern } & \multicolumn{3}{|l|}{ Number of cases } & \multirow[b]{2}{*}{$\begin{array}{l}\text { P value } \\
\text { (1 vs. } 6)\end{array}$} \\
\hline & $\begin{array}{l}1 \text { month }(\mathrm{N}=60) \\
\text { Frequency }(\%)\end{array}$ & $\begin{array}{l}3 \text { months }(\mathrm{N}=58) \\
\text { Frequency }(\%)\end{array}$ & $\begin{array}{l}\text { 6months }(\mathrm{N}=58) \\
\text { Frequency }(\%)\end{array}$ & \\
\hline Irregular heavy bleeding & $22(36.7 \%)$ & $13(22.4 \%)$ & $2(3.4 \%)$ & $0.000 *$ \\
\hline Spotting & $36(60.0 \%)$ & $39(67.2 \%)$ & $14(24.2 \%)$ & $0.008 *$ \\
\hline Normal menses & $0(0.0 \%)$ & $4(6.9 \%)$ & $8(13.8 \%)$ & $0.006^{*}$ \\
\hline Oligomenorrhea/amenorrhea & $0(0.0 \%)$ & $2(3.4 \%)$ & $32(53.3 \%)$ & $0.000 *$ \\
\hline
\end{tabular}

* Statistically significant, Chi square test used.

Table 4: LNG-IUS: outcome at the end of six month.

\begin{tabular}{|lcl|}
\hline Outcome & N & $\%$ \\
\hline Improved (at the end of six month) & 54 & 90 \\
\hline Expulsion & 02 & 3.33 \\
\hline Removal & 01 & 1.67 \\
\hline Hysterectomy & 01 & 1.67 \\
\hline No improvement & 02 & 3.33 \\
\hline Total & 60 & 100 \\
\hline
\end{tabular}

Table 5: Patients' satisfaction with LNG-IUS.

\begin{tabular}{|c|c|c|}
\hline Satisfaction level & $\mathbf{N}$ & $\%$ \\
\hline Not satisfied ( $(0$ to 3 ) & 4 & 6.67 \\
\hline Satisfied (4 to 7 ) & 4 & 6.67 \\
\hline Very satisfied (8-10) & 52 & 86.66 \\
\hline Total & 60 & 100 \\
\hline
\end{tabular}

This was same as in the study by Dhamangaonkar et al in which 1 patient spontaneously expelled LNG IUS within one month of expulsion while in the study by Singh et al there was spontaneous expulsion of the device in 2 patients in first 3 menstrual cycles. In our study only 1 woman requested for the removal of LNG- IUS and 1 woman opted for hysterectomy and this was due to persistent heavy menstrual bleeding this is similar to Singh et al. 2 patients requested for removal of device and opted for hysterectomy due to continue irregular heavy bleeding while in study by Dhamangaonkar et al LNG IUS was removed in 1 patient due to leukorrhea and 4 patients underwent hysterectomy.

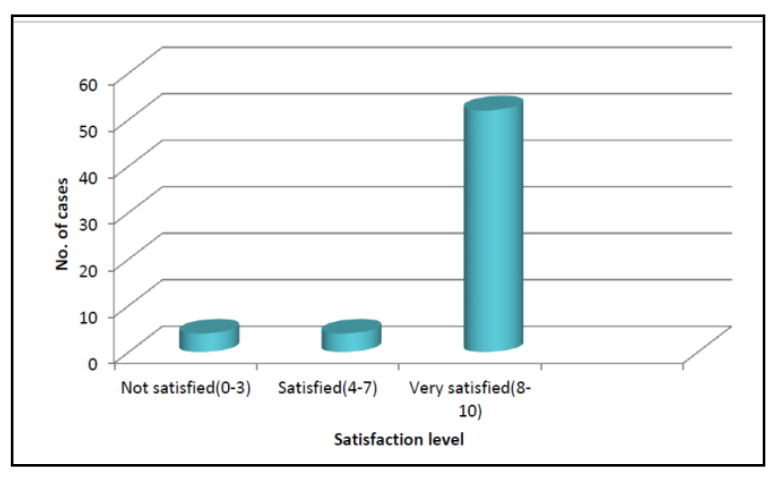

Figure 2: Distribution of cases according to satisfaction level of patients.
LNG-IUS in long-term users causes $70-90 \%$ reduction in blood loss. Hemoglobin, hematocrit, and ferritin levels correspondingly increase during the time of treatment. ${ }^{8}$ $86.66 \%$ of the patients were found very satisfied with the use of levonorgestrel containing intra uterine device and hence this leads to stronger argument to put forward in favor of using LNG-IUS in AUB patients.

\section{Limitations}

Limitations of current study were due to lesser preference and acceptance of LNG IUS as a management option for AUB, our sample size is lower. More acceptability will definitely give more sample size for exploring other areas of concern as well.

\section{CONCLUSION}

LNG-IUS is a safe, effective and first line treatment for AUB. Due to the local effects of LNG-IUS, most of the women experience changes in menstrual pattern. It reduces the menstrual blood loss significantly and at the end of six months $50 \%$ of the women had achieved amenorrhea. Hemoglobin levels increases significantly with its use and thus it helps to improve anemia. It is also effective in the patients with fibroid, adenomyosis and can be used safely in patients with other medical comorbidities, in whom surgery can't be done. Counselling plays an important role in continuation of device and adjusting women with the change of bleeding pattern. Thus our study concluded that LNG-IUS is an effective device for medical management of AUB and it should be used as the first line therapy for the same. It should always be considered before surgical interventions. LNG-IUS improves overall quality of life of the women and the level of patient satisfaction observed is significant.

Funding: No funding sources

Conflict of interest: None declared

Ethical approval: The study was approved by the Institutional Ethics Committee

\section{REFERENCES}

1. Cooper JM. Contemporary management of abnormal uterine bleeding. Preface. Obstet Gynecol Clin North Am. 2000;27:11-3. 
2. Sharma A, Dogra Y. Trends of AUB in tertiary centre of Shimla hills. J Midlife Health. 2013;4:67-8.

3. Padubidri VG, Daftary SN. Shaw's textbook of gynaecology,16th ed. Netherlands: Elsevier; 2014.

4. Singh K, Prasad D, Bharati G, Kumari S. Role of levonorgestrel releasing intrauterine device in management of heavy menstrual bleeding: a conservative approach. Int J Reprod Contracept Obstet Gynecol. 2017;6:631-5.

5. Dhamangaonkar PC, Anuradha K, Saxena A. Levonorgestrel intrauterine system (Mirena): An emerging tool for conservative. J Midlife Health. 2015;6:45-9.

6. NICE guidelines for Heavy menstrual bleeding: assessment and management. Available at: https://www.nice.org.uk/guidance/ng88. Accessed on 20 August 2021.
7. Cim N, Soysal S, Sayan S, Yildizhan B, Karaman E, Cetin $\mathrm{O}$, et al. Two years follow-up of patients with abnormal uterine bleeding after insertion of the levonorgestrel-releasing intrauterine system. Gynecol Obstet Invest. 2018;83(6):569-75.

8. Shulman LP, Nelson AL, Darney PD. Recent developments in hormone delivery systems. Am J Obstet Gynecol. 2004;190:39-48.

Cite this article as: Dave A, Sinha K, Gupta N. Assessment of patient satisfaction after levonorgestral containing intrauterine system insertion in women with abnormal uterine bleeding Int J Reprod Contracept Obstet Gynecol. 2022;11:160-4. 